- Revista de Iniciação à Docência, v. 2, n. 1, 2017 -

Publicação: dezembro, 2017 - ISSN 2525-4332

\title{
QUÍMICA ESCOLAR: PERCEPÇÕES E EXPECTATIVAS DE ESTUDANTES DO ENSINO MÉDIO
}

\author{
Ana Luiza de Quadros ${ }^{1}$ \\ Adriana Araújo Dutra Rodrigues ${ }^{2}$ \\ Carlos Alberto R. Lares 3 \\ Dayse Carvalho da Silva Martins 4 \\ Fernanda Antunes de Almeida Moraes 5 \\ Fernando Henrique Silva de Figueiredo ${ }^{6}$ \\ Renata Fonseca Ferreira ${ }^{7}$
}

RESUMO: Os jovens adolescentes que frequentam o Ensino Médio demonstram grande capacidade de engajamento em situações que lhes são atrativas: banda favorita, jogos eletrônicos, time de futebol etc. No entanto, muitos deles demonstram resistência no engajamento com os conteúdos químicos tratados nas escolas. Com o objetivo de entender o que envolve ou poderia envolver os estudantes nas aulas de Química e a percepção de cada um sobre a disciplina, desenvolvemos este trabalho. Aplicamos um instrumento de coleta de dados para quatro turmas de estudantes do Ensino Médio e, por meio da análise, percebemos que os estudantes têm desejos que são compatíveis com a aprendizagem em Química: querem participar mais, querem aulas diversificadas, entre outros desejos. É indicado que nós, professores, assumamos posturas mais voltadas aos anseios dos estudantes conjugando, com isso, a necessária aprendizagem.

Palavras-Chave: Química; Ensino Médio; Engajamento; Ensejos.

\section{Introdução}

Nossa experiência com jovens adolescentes permite perceber a capacidade impressionante de cada um deles em reconhecer a "marca" da moda, em descrever a história e o repertório da banda favorita, em fazer a escalação nominal do seu time de futebol, bem como a projeção na tabela de classificação do campeonato e em relatar as novidades que circulam na televisão. São experts, ainda, em jogos eletrônicos, em

\footnotetext{
${ }^{1}$ Professora adjunta do Departamento de Química da Universidade Federal de Minas Gerais, Belo HorizonteMG, Brasil. E-mail: ana.quadros@uol.com.br

${ }^{2}$ Mestre em Educação pela Universidade Federal de Minas Gerais e Professora de Química de Ensino Médio do Governo do Estado de Minas Gerais, Belo Horizonte-MG, Brasil. E-mail: dri_chano4@hotmail.com

3 Graduado em Química pelo Departamento de Química da Universidade Federal de Minas Gerais, Belo Horizonte-MG, Brasil. E-mail: clares@ufmg.br

4 Professora adjunta do Departamento de Química da Universidade Federal de Minas Gerais, Belo Horizonte-MG, Brasil. E-mail: daysecsm@yahoo.com.br

5 Graduada em Química pelo Departamento de Química da Universidade Federal de Minas Gerais, Belo Horizonte-MG, Brasil. E-mail: ferantalma@yahoo.com.br

${ }^{6}$ Graduado em Química pelo Departamento de Química da Universidade Federal de Minas Gerais, Belo Horizonte-MG, Brasil. E-mail: nandohsf@qui.grad.ufmg.br

7 Graduada em Química pelo Departamento de Química da Universidade Federal de Minas Gerais, Belo Horizonte-MG, Brasil. E-mail: refonsecaf@qui.grad.ufmg.br
} 
- Revista de Iniciação à Docência, v. 2, n. 1, 2017 -

Publicação: dezembro, 2017 - ISSN 2525-4332

programas de computador desconhecidos pelo mundo "adulto", navegam com facilidade pelas redes de relacionamento e, enfim, em todas as novidades tecnológicas do momento. Em contrapartida, os professores desses mesmos jovens comentam, não raras vezes, sobre o pouco interesse em relação ao conhecimento veiculado nas disciplinas escolares e como eles se limitam, em muitos casos, apenas ao necessário para serem aprovados na série em que frequentam ou em exames, como é o caso do ENEM e do vestibular.

Essa é uma constatação que, sem dúvida, nos deixa intrigados. O que poderia, na escola, envolver os estudantes com o conteúdo vinculado nas diferentes disciplinas, tanto quanto eles se envolvem com os assuntos cotidianos, como os citados acima? No caso da Química, quais fatores auxiliariam o interesse dos alunos por esta ciência?

Sabemos que a sociedade mudou e que a escola está longe de ser o único local no qual as informações podem ser encontradas. A disseminação dos livros, revistas, bibliotecas e, principalmente, da rede mundial de informação e comunicação - internet faz com que a informação esteja acessível a todos, independentemente de frequentarem a escola. No entanto, muitas escolas continuam desenvolvendo aulas com características que as colocam mais como informadoras, por entenderem a atividade docente como simples transmissão de informações, do que como formadoras de sujeitos capazes de viver melhor no mundo, porque entendem e se relacionam bem com os fatos/fenômenos da natureza.

Por meio de uma reflexão sobre o componente curricular Química, reconhecemos ser esta uma ciência cujo entendimento exige capacidade de abstração. Exatamente por isso, estudantes a consideram uma matéria/disciplina "distante", difícil e sem muita utilidade prática. Muitos educadores (BRASIL, 2000; MORTIMER; SCOTT, 2002; MALDANER, 2000; SCHNETZLER, 2002), baseados nas tendências contemporâneas de ensino, têm defendido a contextualização, a interdisciplinaridade, o uso de aulas dialogadas e, em uma perspectiva construtivista, um ensino que parta dos conhecimentos prévios dos estudantes e explore as ideias de cada um, fazendo-os evoluir.

Mesmo com mais de uma década de "novas" diretrizes curriculares no Brasil e de intensos debates em torno das tendências contemporâneas de ensino, principalmente aquelas presentes nos Parâmetros Curriculares Nacionais (BRASIL, 2000), a escola continua, para alguns estudantes, pouco atrativa. Nossa prática como professores da educação básica e com os estágios de licenciatura tem mostrado, nas salas de aula, estudantes com fones de ouvido, que desenvolvem conversas paralelas ao que é discutido em classe e que não demonstram interesse pelo que é ensinado durante as aulas. 
- Revista de Iniciação à Docência, v. 2, n. 1, 2017 -

Publicação: dezembro, 2017 - ISSN 2525-4332

Diante disso, nosso trabalho busca, em uma amostra de estudantes do Ensino Médio, identificar alguns fatores que poderiam engajar os estudantes nas aulas e, assim, melhorar o desempenho tanto do professor quanto dos próprios estudantes.

\section{Referencial Teórico}

Nossa experiência com estágios e com a formação inicial e continuada de professores mostra que a falta de interesse dos estudantes com o conteúdo escolar é uma das reclamações constantes dos professores. A origem deste suposto desinteresse pode ser consequência direta das opções feitas pelo professor, em termos de seleção de conteúdo, metodologia etc., ou um desencontro de interesses, manifestado por aquilo que a escola considera importante para o sujeito aprendiz e aquilo que ele realmente busca.

Barros et al. (2004) assinalam que uma das razões do desinteresse pelo estudo na escola é o modelo passivo de aprendizado, no qual o professor fala e os estudantes apenas escutam, ou seja, não há ocorrência de diálogo. O professor como transmissor de informações e os estudantes como meros receptores dessa informação. Essa proposta de trabalho tem sido chamada de abordagem tradicional. Por meio dessa abordagem, os estudantes interagem pouco e o estímulo para estudar está mais voltado para as notas (avaliação) do que para o conhecimento. Nesse modelo passivo de ensino, os estudantes encontram meios de memorizar, às vésperas das provas, o conteúdo ministrado, para garantir as notas necessárias, porém não a aprendizagem desejada. Barros et al. (2004) argumentam que o estudo esporádico, com um fim específico, faz com que o conteúdo seja desconexo, diminuindo ainda mais o interesse dos estudantes.

Partimos da ideia quase universalizada de que a aprendizagem depende do envolvimento dos estudantes nas atividades propostas, ou seja, do engajamento deles no processo de ensino-aprendizagem. Entendemos por engajamento a relação que o estudante estabelece com as atividades que lhes são propostas no contexto da sala de aula. Segundo Fredricks, Blumenfeld e Paris (2004), essa relação envolve aspectos comportamentais, emocionais e cognitivos. Quando tratamos da participação e do envolvimento dos estudantes em atividades escolares e em atividades extracurriculares e das condutas positivas empreendidas durante a resolução as atividades, estão envolvidos os aspectos comportamentais. Se tratamos das reações afetivas e emocionais (por exemplo: interesse, bem-estar, desgosto, ansiedade) dos estudantes diante das atividades, então estão envolvidos os aspectos emocionais. No entanto, se envolvermos o esforço empreendido pelo estudante para compreender o que é estudado a fim de atingir níveis mais elevados de compreensão sobre determinado tópico de estudo, então o engajamento envolve fatores cognitivos. Inúmeros estudos (AINLEY, 1993; CONNELL, SPENCER; ABER, 1994; MARKS, 2000; SINGH; GRANVILLE; DIKA, 2002; BORGES; JULIO; COELHO, 2005; FARIA, 2008) são encontrados na literatura, apontando para a estreita relação entre o engajamento, o rendimento escolar e o desenvolvimento social e 
- Revista de Iniciação à Docência, v. 2, n. 1, 2017 -

Publicação: dezembro, 2017 - ISSN 2525-4332

cognitivo dos estudantes. Concordamos com Faria (2008) quando o autor afirma que compreender "[...] quais elementos contextuais interferem no engajamento dos estudantes e entender como esses elementos favorecem ou limitam o engajamento em diferentes situações de aprendizagem parece muito importante" (p. 9), uma vez que cria a possibilidade de o professor interferir conscientemente na aula e potencializar o engajamento dos estudantes nas atividades propostas.

Vários são os fatores descritos na literatura para justificar o pouco engajamento dos estudantes com o conteúdo escolar. Quando esse pouco engajamento não é compreendido, a falta de interesse dos estudantes acaba desestimulando o educador a buscar metodologias de ensino mais inovadoras e de avaliação mais criativa (LIMA; VASCONCELOS, 2006). Neste sentido, Strack, Marques e Del Pino (2009) afirmam que:

[...] a prática docente de muitos professores atualmente está comprometida com um currículo rígido, que prestigia conteúdos desconectados entre si (ausência de interdisciplinaridade) e, sobretudo, [desconectados] da realidade dos alunos, situação que cria a desvalorização da aula como um local de construção e mudança, tanto dos alunos quanto dos próprios professores (STRACK; MARQUES; DEL PINO, 2009, p. 18-19).

No caso da disciplina de Química, isto nos parece ainda mais explícito. É comum ouvirmos estudantes de ensino médio se referindo à Química escolar como difícil, abstrata e desnecessária, entre outros comentários. Geralmente, os programas propostos são tão extensos que não conseguem ser finalizados ou os conceitos fundamentais acabam por ser superficialmente ensinados. Nesses casos, corre-se o risco de uma construção errônea dos conceitos e da falta de relação destes com os já ensinados e/ou com o contexto social.

De acordo com Chassot (1990) o ensino de Química deveria estar ligado aos acontecimentos cotidianos, para desenvolver no estudante uma visão crítica sobre o mundo em que vivemos. Lopes (2005) destaca a relevância de certos conceitos e teorizações e argumenta sobre a análise dos processos de organização e constituição do conhecimento escolar, por meio da integração curricular e dos diferentes processos de mediação que constituem esse conhecimento. Isso inclui a transposição e a mediação didática e processos envolvendo, de forma adequada, o uso de metáforas e analogias.

Quando se enfatiza a quantidade do conteúdo e não a sua relevância, é provável que o professor opte pela transmissão organizada de informações, que lhe permite fornecer maior número de informações, mas, diminui sua atenção para o processo de significação dessa informação. Isso pode estar colaborando para que os estudantes não tenham interesse e não se dediquem ao estudo, criando um ciclo de não entendimento dos conceitos nos estudantes e de desmotivação dos próprios professores.

O desinteresse dos estudantes em relação ao conteúdo escolar, assim como o insucesso escolar, a apatia e a passividade são frequentemente associados à falta de motivação dos estudantes. Segundo Lemos (1993), tanto no plano da prática pedagógica, 
- Revista de Iniciação à Docência, v. 2, n. 1, 2017 -

Publicação: dezembro, 2017 - ISSN 2525-4332

quanto no da investigação científica, a motivação surge a partir da década de 1970, como fator relevante nos contextos escolares, sendo evidenciada como determinante do sucesso escolar e como finalidade educativa em si mesma.

Lemos (1993) discute a relação entre o valor do ensino que é oferecido aos estudantes com aquilo que os estudantes desejam. Ela argumenta que aquilo que o professor julga estar ao alcance de seus estudantes, nem sempre é aquilo com o qual eles querem se envolver ou aquilo que os sujeitos desejam para si (ou acham que devem fazer). Ela afirma que:

Há muitas ações em que os sujeitos não se envolvem, apesar de terem a certeza de as conseguir realizar. Por outro lado, os sujeitos envolvem-se em ações apesar de não estarem seguros da sua competência para as realizar. [...]. Tratase de variáveis relacionadas com o valor de que as atividades ou objetos do ambiente se revestem para o sujeito (LEMOS, 1993, p. 103).

A referida autora usa o conceito de desejabilidade para se referir ao valor que os estudantes dão para determinadas atividades escolares e argumenta que este é um fator relevante para a motivação. Já para Cardoso e Colinvaux (2000), ao se referirem às teorias contemporâneas de ensino e aprendizagem, comparando-as com os currículos de Química assinalam que:

Devido ao fato de viver em sociedade, adquirimos um conhecimento que tornase progressivamente mais estruturado e claro por estarmos continuamente discutindo, elaborando e reelaborando nossas ideias com outros. Por outro lado, o contexto escolar muitas vezes não possibilita uma maior discussão entre os alunos acerca dos conhecimentos adquiridos, seja por limitação de tempo ou ainda devido à inadequação de nossos currículos e práticas pedagógicas (CARDOSO; COLINVAUX, 2000, p. 401).

Para estes autores, a motivação pelo estudo, principalmente de Química, será alcançada quando as aulas baseadas na simples memorização de nomes e fórmulas forem abandonadas, tornando-se vinculadas aos conhecimentos e conceitos do dia-a-dia dos estudantes. Neste estudo, Cardoso e Colinvaux (2000) investigaram a relação dos estudantes com a Química e, entre os estudantes que gostam de Química, as justificativas para este "gostar" foram a atração pelos fenômenos da natureza, o valor da disciplina para o desenvolvimento dos sujeitos, as aulas práticas, a utilidade para a vida e/ou profissão. Entre aqueles que não gostam de Química, as justificativas foram o excesso e a dificuldade dos conteúdos, a inutilidade dos conteúdos escolares, a dificuldade em entender ou assimilar os conteúdos e a presença de outras áreas como Matemática e Física.

Arroio et al. (2006) citam que a mídia, sempre relacionando a Química com coisas nocivas, ruins para o ser humano, desperta nos estudantes um sentimento negativo associado ao componente curricular "Química”. Para ampliar esta visão de Química, os autores tratam de fatores que estimulam outros sentimentos nos estudantes, deixando- 
- Revista de Iniciação à Docência, v. 2, n. 1, 2017 -

Publicação: dezembro, 2017 - ISSN 2525-4332

os mais abertos para o ensino, mais motivados a aprender e entender o mundo à sua volta e, consequentemente, mais abertos para o estudo dessa Ciência.

Desenvolvemos este trabalho com o objetivo de entender alguns fatores que favorecem ou diminuem o interesse dos estudantes pelas aulas de Química e, consequentemente, o engajamento dos mesmos com o estudo dessa ciência. Para isso, julgamos que o caminho mais coerente seria buscar indícios nos próprios estudantes de como eles se relacionam com a Química escolar.

\section{Metodologia}

Segundo Garnica (1997), a pesquisa qualitativa é entendida como uma trajetória circular em torno do que se deseja compreender, voltando o olhar para a qualidade e para os elementos que são significativos para o pesquisador. Assim, este trabalho teve características da pesquisa qualitativa. Além disso, fez uso de um instrumento de coleta de dados e da análise qualitativa desses dados. Para melhor explicitá-las, faremos a caracterização do campo investigado e a descrição das ações desenvolvidas.

\section{a) Caracterização do campo de investigação:}

O presente trabalho foi realizado com estudantes de quatro turmas de Ensino Médio, sendo uma turma de primeiro ano, uma de segundo ano, uma de terceiro ano e uma turma atípica, cujos integrantes frequentam as aulas em caráter informal, com o intuito de se atualizarem, tanto para retornar ao ensino formal (aqueles que pararam de estudar há alguns anos) ou para enfrentar o processo de seleção para o Ensino Superior. Tivemos, então, a participação de 110 estudantes, sendo 57 de escolas particulares e 53 de escolas públicas. Os estudantes das três séries estão em idade normal de escolarização, ou seja, entre 15 a 18 anos e os estudantes da classe especial têm idades que variam de 18 a 47 anos. Essas quatro turmas foram escolhidas por representarem estudantes que têm tempo diferente de relação com a Química escolar.

\section{b) As ações empreendidas:}

Construímos um instrumento de coleta de dados - um questionário - com cinco questões, que serão descritas posteriormente durante a discussão dos dados coletados. A primeira delas buscava o entendimento que esses estudantes tinham sobre a ciência Química, principalmente em termos de sua relação com o mundo. As quatro questões seguintes foram construídas com o intuito de identificar a relação desses estudantes com a Química escolar.

Aplicamos o questionário aos estudantes, em horário normal de aula e lhes foi fornecido o tempo necessário para responderem. O tempo médio requerido pelos estudantes foi de 15 minutos. Em posse dos questionários, fizemos a leitura conjunta das respostas, construindo as categorias de análise. Agrupamos, então, as respostas por semelhança, em categorias que emergiram dos dados. As respostas fornecidas pelos estudantes às questões propostas foram analisadas em um primeiro momento para gerar 
- Revista de Iniciação à Docência, v. 2, n. 1, 2017 -

Publicação: dezembro, 2017 - ISSN 2525-4332

as categorias e, em um segundo momento, para agrupar cada resposta dentro da categoria condizente a ela.

\section{Resultados e Discussão}

Para a primeira questão, solicitamos aos estudantes que, ao pensarem em Química, escrevessem as três primeiras palavras que lhes viessem à mente. As respostas obtidas, ilustradas por meio da Figura 1, mostram que, apesar do instrumento de coleta de dados não ter sido aplicado durante as aulas de Química, a relação que fizeram com a disciplina escolar foi grande. Dos 110 estudantes que participaram deste estudo, 108 usaram palavras relacionadas à disciplina, seja através de conceitos (átomo, molécula, fórmulas, tabela periódica etc.) ou por meio de sentimentos relacionados à disciplina (dificuldade, complexa etc.). Apenas dois deles citaram palavras (ciência, farmácia, descobertas e avanços) que mostram uma visão mais ampla de Química ou que extrapolaram a Química escolar.

Figura 1. Nuvem das palavras citadas pelos estudantes na questão 1. 0 tamanho das palavras indica a frequência com que as palavras apareceram (Ex: átomo - 16 vezes; laboratório - 2 vezes).

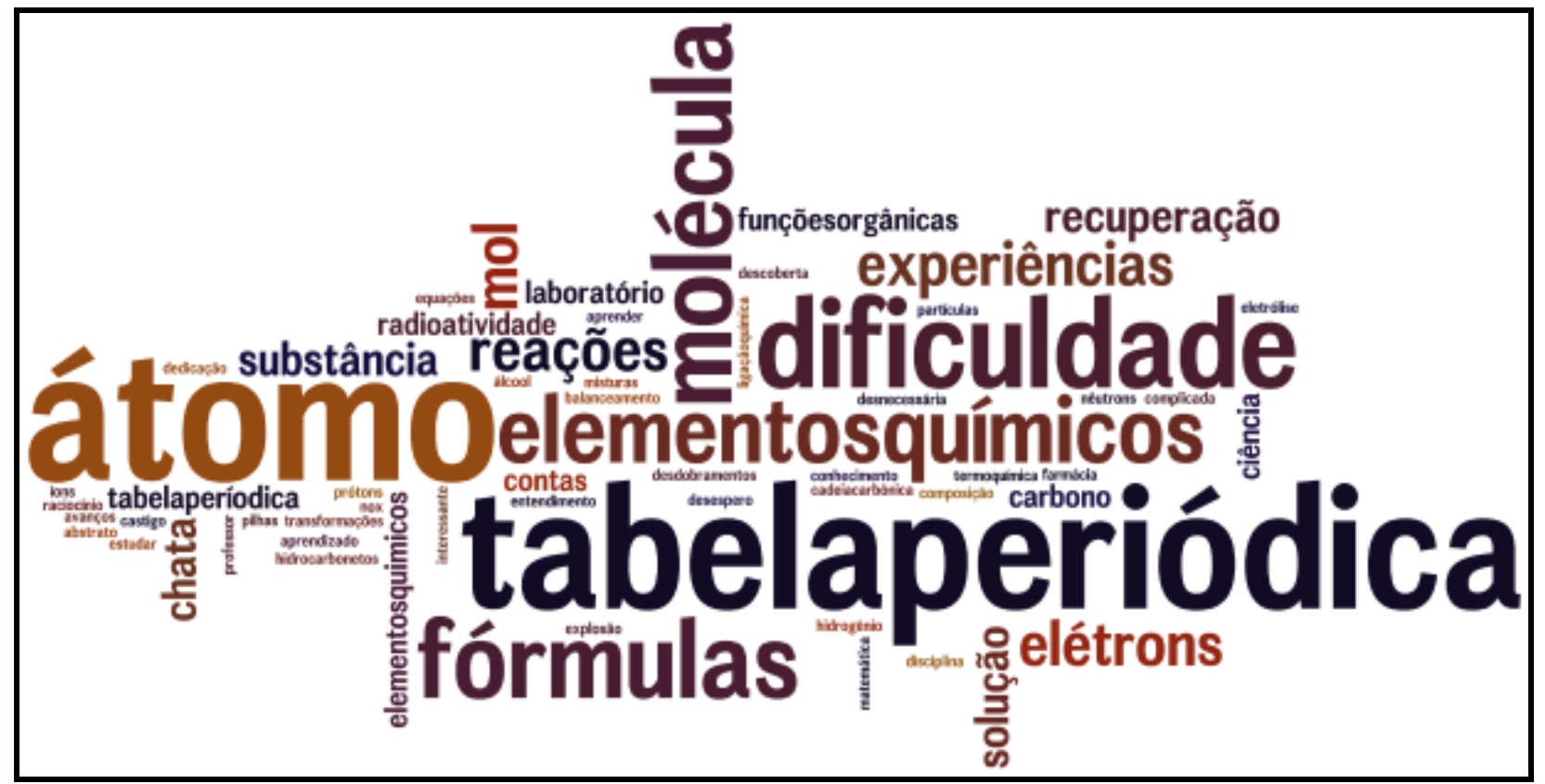

Fonte: Elaborado pelos autores

Esse resultado pode representar apenas o fato de que, por estarem na escola, os estudantes consideraram que o instrumento de coleta de dados se referia à química escolar. Porém, acreditamos que esses estudantes não foram capazes de perceber, até então, que os conteúdos estudados na escola representam a explicação da ciência sobre os fenômenos e os materiais que compõe o mundo físico em que vivem. Em nossa opinião, se os estudantes tivessem entendido o conhecimento químico como uma explicação para os fenômenos do mundo, um número maior deles teria extrapolado a 
- Revista de Iniciação à Docência, v. 2, n. 1, 2017 -

Publicação: dezembro, 2017 - ISSN 2525-4332

sala de aula ao escolher as palavras para escrever o solicitado na primeira questão proposta no questionário.

O segundo questionamento foi dividido em dois subitens, ou seja, i) "Se você fosse contar a um amigo sobre a disciplina de Química da escola, o que você diria?" e ii) "Em relação às demais disciplinas escolares, como é a Química?". Apesar de dividirmos a questão em dois subitens, as respostas obtidas foram analisadas conjuntamente, já que ambas mostram a opinião dos participantes sobre o conhecimento químico desenvolvido nas escolas. Usamos um amigo imaginário para que, por meio de um diálogo fictício, o estudante discorresse de forma mais fluente os seus comentários sobre o componente curricular Química.

É possível notar na Tabela 1 que algumas respostas se encaixaram em mais de uma categoria, fazendo com que o número total de respostas fosse maior do que o número de participantes. Percebemos, inicialmente, um maior número de respostas se referindo à disciplina Química de forma positiva. As categorias de respostas e o número total em que foram mencionadas são apresentados na Tabela 1.

Tabela 1. Comentário dos estudantes sobre a disciplina Química.

\begin{tabular}{c|l|c|c}
\hline \multicolumn{2}{c|}{ Categorias } & Número Total & $\begin{array}{c}\text { Porcentagem de estudantes com } \\
\text { esta opinião (\%) }\end{array}$ \\
\hline \multirow{4}{*}{ Positiva } & Interessante & 39 & 35,5 \\
\cline { 2 - 4 } & Gosta & 35 & 31,8 \\
\cline { 2 - 4 } & Importante & 16 & 14,5 \\
\cline { 2 - 4 } & Divertida & 3 & 2,7 \\
\hline \multirow{4}{*}{ Negativa } & Complexa & 31 & 28,2 \\
\cline { 2 - 4 } & Não atrativa & 19 & 17,3 \\
\cline { 2 - 4 } & Exige atenção & 12 & 10,9 \\
\cline { 2 - 4 } & Não gosta & 5 & 4,5 \\
\hline
\end{tabular}

Fonte: Elaborado pelos autores.

Nossa experiência mostra que a Química engloba uma gama de conteúdos considerados difíceis, dos quais os estudantes gostam menos. Nos comentários que geraram os termos "complexa" e "exige atenção" os estudantes se referiam à Química como um componente curricular que, por mais que se esforçassem, não conseguiam entender e, por isso, não gostavam. Entretanto, das 160 manifestações advindas dos 110 estudantes, 93 foram positivas e 67 negativas. Muitos estudantes se referiram à disciplina como interessante. Nessa categoria, foram colocados os comentários que demonstravam interesse por Química, sendo que a grande maioria usou explicitamente a palavra "interessante".

O termo "gostar" foi usado, algumas vezes, sem a explicitação dos motivos que os levavam a gostar da referida disciplina. Outros 16 estudantes a reconhecem como 
- Revista de Iniciação à Docência, v. 2, n. 1, 2017 -

Publicação: dezembro, 2017 - ISSN 2525-4332

importante, tanto para a própria formação, referindo-se, inclusive, a conhecer o mundo. Outros três a denominaram como divertida. Dentre as reações que classificamos como negativas, a mais recorrente é que se trata de uma matéria "complexa" ou "complicada", com 31 citações. A categoria "não atrativa" relacionou respostas que se referiam à disciplina como "chata" ou "entediante" e que, diferente da categoria anterior, envolve estudantes que demonstraram apatia pela disciplina.

A categoria "exige atenção" pode conter opiniões de estudantes que se interessaram pelo conteúdo e que, talvez, tenham apenas identificado a complexidade de alguns conhecimentos. No entanto, a maior parte deles nos pareceu mais próximos a comentários negativos. Uma citação que exemplifica este comentário é de que o conteúdo "exige atenção em comparação com outras disciplinas". Implicitamente, esta citação afirma a existência de disciplinas nas quais a atenção dispensada pode ser menor. Só não fica claro se é porque essas disciplinas são menos importantes, menos difíceis ou mais atraentes que a Química.

Apenas cinco estudantes declararam explicitamente que não gostam de Química, sem justificar seus posicionamentos. É interessante notar que, na amostra pesquisada, os estudantes tendem a gostar de Química, ou, pelo menos, perceber sua importância. Com isso, pode-se dizer que, de maneira geral, a maior parte do grupo de estudantes participantes deste estudo demonstra "atração" pela Química, o que, em teoria, aumentaria sua motivação para seu estudo. Buscamos confirmar ou refutar essa observação por meio da análise das respostas às questões seguintes do questionário.

Na questão seguinte solicitamos a descrição de uma aula da qual o estudante não tenha gostado. A questão proposta foi a seguinte: "Frequentemente, estudantes reclamam que a aula que estão assistindo é uma 'perda de tempo' e preferiam estar fazendo outra coisa nessa hora. Você já se sentiu assim na aula de Química? Descreva como estava a aula nessa situação". Esperávamos que os estudantes, caso tivessem vivido esse tipo de experiência, a relatassem. Entre os participantes, 46 afirmaram não ter tido este tipo de experiência.

Entre os que descreveram alguma situação, os relatos indicam as características da aula ou o motivo pelo qual se sentiram assim. A Tabela 2 apresenta as categorias oriundas da análise dessa questão. 
- Revista de Iniciação à Docência, v. 2, n. 1, 2017 -

Publicação: dezembro, 2017 - ISSN 2525-4332

Tabela 2. Comentário dos estudantes sobre aula que julgou “perda de tempo”a.

\begin{tabular}{l|c|c}
\hline \multicolumn{1}{c|}{ Categoria } & $\begin{array}{c}\text { Número de } \\
\text { respostas }\end{array}$ & $\begin{array}{c}\text { Porcentagem de } \\
\text { estudantes (\%) }\end{array}$ \\
\hline Fator pessoal do estudante & 14 & 21,9 \\
\hline Falta de disciplina da turma & 14 & 21,9 \\
\hline Conteúdo sem relação com a vida & 13 & 20,3 \\
\hline Críticas ao trabalho do professor & 11 & 17,2 \\
\hline Aula não interativa & 9 & 14,1 \\
\hline Conteúdo já conhecido & 4 & 6,3 \\
\hline Atividade proposta difícil & 1 & 1,6 \\
\hline
\end{tabular}

${ }^{a}$ Dois estudantes fizeram comentários que se enquadraram em duas categorias. Por isso, o número total de respostas é 66 . b Porcentagem calculada em relação àqueles que tinham experiência a compartilhar, ou seja, 64 estudantes. Fonte: Elaborada pelos autores.

As duas categorias com maior número de citações não se referem a aspectos do conteúdo tratado nas aulas. Motivos próprios dos estudantes (dor de cabeça, problemas familiares e outros motivos) e o comportamento inadequado da turma apareceram como fatores importantes. O primeiro motivo está relacionado ao estudante e não com a turma ou com o tipo de aula e o segundo está relacionado com o gerenciamento da classe. $O$ conteúdo de Química, sem relação com a vida, também foi bastante citado. Nesse caso, os estudantes provavelmente não estão conseguindo perceber a "utilidade" do conhecimento trabalhado em aula e este, certamente, é um fator desmotivador. Outro grupo de estudantes fazem críticas ao trabalho dos professores. Nesta categoria estão os comentários sobre o pouco compromisso do professor com as aulas ou de explicações pouco estruturadas, que não ficam claras para os estudantes. A passividade, conforme já argumentado, não é própria dos jovens dessa idade escolar. Eles desejam participar mais das aulas, dar opiniões, argumentar quando possível. O debate em torno de ideias estimula a imaginação e, quando devidamente conduzido, facilita a evolução conceitual dos estudantes. Esse motivo foi apontado por 9 estudantes, mostrando que mesmo em pequeno número, eles querem ter papel ativo na sua formação e na construção de seu conhecimento. Também percebemos que a repetição de conteúdos é desestimulante: 4 estudantes afirmaram se sentir entediados quando a aula gira em torno de conteúdos já conhecidos. Isso é indício de que eles querem aprender e desejam que as aulas os permitam evoluir intelectualmente. Para um único pesquisado uma atividade muito difícil foi vista como desestimulante. Nesse caso, não se tratava de uma atividade desafiadora, mas algo que estava aquém de suas possibilidades.

Na quarta questão, "Em oposição ao descrito na questão anterior, algumas vezes ficamos tão envolvidos com uma atividade que não vemos o tempo passar. Durante aulas de Química isso já aconteceu com você? Caso tenha acontecido, descreva tudo o que lembra sobre o fato (o que estava acontecendo, qual conteúdo, o que a professora ou professor fazia etc.)", esperávamos que os estudantes descrevessem as características de uma aula na qual tivessem se envolvido de forma mais intensa, isto é, eles estavam engajados com a situação. As respostas obtidas estão na Tabela 3. 
- Revista de Iniciação à Docência, v. 2, n. 1, 2017 -

Publicação: dezembro, 2017 - ISSN 2525-4332

Tabela 3. Características de uma boa aula de Química já vivenciada ${ }^{a}$.

\begin{tabular}{|c|c|c|c|}
\hline \multicolumn{2}{|c|}{ Categoria } & $\begin{array}{c}\text { Número de } \\
\text { respostas }\end{array}$ & $\begin{array}{l}\text { Porcentagem de } \\
\text { estudantes }(\%)^{\mathrm{b}}\end{array}$ \\
\hline \multicolumn{2}{|l|}{ Experimento/prática } & 24 & 35,8 \\
\hline \multicolumn{2}{|l|}{ Exercícios } & 20 & 29,9 \\
\hline \multirow{2}{*}{ Estratégias do Professor } & Uso de esquemas & 9 & 13,4 \\
\hline & Brincadeiras & 8 & 11,9 \\
\hline \multicolumn{2}{|c|}{ Conteúdos contextualizados } & 7 & 10,4 \\
\hline \multicolumn{2}{|l|}{ Aula Interativa } & 4 & 6,0 \\
\hline \multicolumn{2}{|l|}{ Não descreveu/Não lembra } & 43 & - \\
\hline
\end{tabular}

a Alguns estudantes fizeram comentários que se enquadraram em duas categorias. Por isso, o número total de respostas é 115 . b Porcentagem calculada em relação àqueles que tinham experiência a compartilhar, ou seja, 67 estudantes. (Fonte: Autoria Própria)

Observamos um grande número de estudantes (43) que afirma não se lembrar de uma aula assim ou que não foram capazes de descrever uma aula dessas. Isso pode representar uma evidência de que as aulas de Química que estes 43 estudantes assistem são consideradas, por eles, como monótonas. Esses estudantes ainda não tiveram seus interesses despertados, a ponto de se engajarem nas atividades.

Em relação aos que descrevem uma aula com as características solicitadas, a categoria que obteve mais respostas refere-se às aulas experimentais. Podemos dizer que aulas experimentais produzem encantamento, tanto pela possibilidade de interagir (ver, tocar, se movimentar pela sala), quanto pela possibilidade de interferir no processo, por meio da coleta de dados, teste de hipóteses etc. É possível que este tipo de encantamento esteja presente. Porém, aprender também encanta! E um experimento pode ser útil para engajar os estudantes na aula, na medida em que o professor use estratégias adequadas. Vários educadores brasileiros (SILVA; MACHADO, 2008; SILVA; ZANON, 2000; GIORDAN, 1999) têm discutido o papel da experimentação no Ensino de Química enfatizando a triangulação fenômeno, modelo ou teoria e representação. Neste contexto, acreditamos que os experimentos podem produzir aprendizagens significativas e, com isso, conquistar os estudantes para esta ciência.

Um número também significativo de estudantes citou os exercícios como uma atividade feita por eles que seria menos entediante do que as aulas. Se lembrarmos de que na questão anterior 11 estudantes fizeram críticas ao trabalho do professor e outros 9 reclamaram de aulas não interativas, poderíamos pensar que os estudantes preferem os momentos de exercícios em sala de aula porque estes se distanciam dos momentos da aula em que o conteúdo é "transmitido", deixando o aluno em uma postura mais passiva. Ao realizar exercícios, eles podem estar assumindo uma postura mais ativa, ou seja, estão sendo protagonistas. 
- Revista de Iniciação à Docência, v. 2, n. 1, 2017 -

Publicação: dezembro, 2017 - ISSN 2525-4332

Dezessete estudantes destacaram as estratégias empregadas pelo professor, sendo 9 referentes ao uso de esquemas para explicar o conteúdo e outras 8 sobre o uso de brincadeiras em aula, que descontraem o ambiente de estudo. Percebemos que os estudantes valorizam professores que constroem uma boa relação com eles, mesmo que isso ocorra na forma de brincadeiras e, que tentam facilitar a aprendizagem dos estudantes por meio de recursos como esquemas. A categoria seguinte trata de conteúdos com relação direta com o contexto, com 7 respostas. É um indício de valorização desta ciência, quando seus conteúdos estão vinculados ao contexto social. Por fim, obtivemos 4 respostas relacionadas à aulas interativas. Novamente, o estudante se viu envolvido com a aula por estar participando ativamente dela e não atuando como mero receptor de conhecimento.

A última questão proposta no questionário solicitava a descrição de uma aula fictícia. A questão foi a seguinte: "Descreva como seria uma aula de Química da qual você saísse satisfeito porque gostou da aula e porque aprendeu muito". Buscamos nos estudantes as estratégias ou tipo de aulas de Química que eles gostariam de estar participando. Para esta questão, 7 estudantes apenas descreveram uma aula real, que não foi incluída na análise a seguir, e outros 17 não fizeram a descrição da aula. Para os que descreveram (86 estudantes), as respostas dadas foram classificadas nos seguintes grupos representados na Tabela 4.

Tabela 4. Características imaginadas pelos estudantes para uma boa aula de Química .

\begin{tabular}{l|c|c}
\hline \multicolumn{1}{c|}{ Categoria } & $\begin{array}{c}\text { Número de } \\
\text { respostas }\end{array}$ & $\begin{array}{c}\text { Porcentagem de } \\
\text { estudantes (\%) }\end{array}$ \\
\hline Experimento/prática & 47 & 54,7 \\
\hline Crítica ao professor & 17 & 19,8 \\
\hline Relação com o contexto & 13 & 15,1 \\
\hline Recursos diversos & 13 & 15,1 \\
\hline Aula interativa & 8 & 9,3 \\
\hline Turma disciplinada & 7 & 8,1 \\
\hline Aula de campo & 4 & 4,7 \\
\hline Quando representa um desafio & 3 & 3,5 \\
\hline Explicações sem excesso de cálculo & 2 & 2,3 \\
\hline
\end{tabular}

a Alguns estudantes fizeram comentários que se enquadraram em duas categorias. Por isso, o número total de respostas é $114 .{ }^{\text {b }}$ Porcentagem calculada em relação àqueles que descreveram a aula fictícia, ou seja, 86 estudantes. (Fonte: Autoria Própria).

Pela análise da tabela 4, é possível perceber que os maiores motivadores descritos pelos estudantes são a utilização de experimentos, a relação do conteúdo com o contexto, a diversificação das aulas e a oportunidade de serem mais participativos, por meio de aulas interativas. A esses mesmos quatro pontos estão relacionadas as críticas aos professores, referindo-se ao excesso de teoria, à pouca presença de aulas 
- Revista de Iniciação à Docência, v. 2, n. 1, 2017 -

Publicação: dezembro, 2017 - ISSN 2525-4332

experimentais, à apresentação de conteúdos sem relação com o contexto, à pouca participação dos estudantes e à supervalorização do livro didático.

Outras 7 respostas se referiam ao gerenciamento da classe. Nesse caso, os estudantes citaram a conversa de colegas e o comportamento inadequado como prejudiciais ao bom desenvolvimento das aulas. Essas conversas paralelas podem ser decorrência de falta de gerenciamento adequado dos professores. Porém, vale ressaltar que, muitas vezes, a indisciplina pode estar ligada ao fato das aulas não serem atrativas para os estudantes, que preferem conversar e brincar a prestar atenção às explicações do professor. Isso mostra, novamente, o pouco engajamento dos estudantes durante as aulas. Novamente reiteramos que os professores precisam tomar consciência dos fatores que auxiliam no engajamento dos estudantes e, assim, tornar suas aulas mais participativas.

As aulas de campo (visitas a indústrias etc.), o ensino que desafie o estudante e o excesso de cálculos no ensino de Química também apareceram nas aulas fictícias, porém em número reduzido de citações.

\section{O que entendemos a partir dos dados?}

Por meio dos dados obtidos neste trabalho de pesquisa, percebemos que os estudantes esperam dos professores e das aulas de Química aquilo que tanto já se tem dito: algo que conjugue o interesse dos alunos com o que é necessário para que eles consigam explicar o mundo sob o ponto de vista da ciência Química. O desejo de que as aulas envolvam experimentos, que se relacionem ao contexto e que utilizem recursos diversificados é uma evidência de que eles desejam aulas mais dinâmicas. Provavelmente, esses estudantes têm uma participação periférica na dinâmica da sala de aula. E, ao que nos parece, não é isso que eles buscam na escola. Eles querem se sentir sujeitos participativos nas aulas e não meros coadjuvantes. Talvez precisemos entender melhor quais elementos do contexto da sala de aula são capazes de influenciar, positiva e negativamente, a dinâmica da sala de aula e o engajamento dos estudantes.

A Química tem a seu favor a possibilidade de realizar experimentos, tanto em sala de aula, quanto em laboratórios. Vários estudantes citaram uma aula prática ou experimental como um momento de intenso envolvimento com a atividade proposta e, como sugestão, apresentaram esse tipo de atividade. Esses resultados são uma evidência de que os estudantes são motivados pela participação durante as aulas, seja em debates ou em experimentos.

Lemos (1999), ao tratar do conceito de desejabilidade, relaciona aquilo que os estudantes desejam da escola e o que a escola entende serem os conhecimentos e atividades próprios da aprendizagem. O fato de atribuírem características positivas à disciplina também pode ser um indício de que a desejam, mesmo que seja de forma 
- Revista de Iniciação à Docência, v. 2, n. 1, 2017 -

Publicação: dezembro, 2017 - ISSN 2525-4332

diferente. Neste sentido, acreditamos que a desmotivação que alguns estudantes relataram em relação às aulas de Química está mais relacionada à forma como o conhecimento tem sido trabalhado e às atividades que têm sido apresentadas. Com base nos dados obtidos, temos a crença de que os estudantes têm dúvidas quanto à necessidade/importância do estudo da Química.

Sabemos que há um currículo a ser cumprido por cada professor - ligado ao seu planejamento inicial - e há documentos oficiais (Parâmetros Curriculares Nacionais - PCNe outros) tratando da flexibilização dos programas de ensino. É claro que outras questões permeiam esta discussão sobre conteúdos e, entre elas, estão a cobrança da sociedade principalmente alguns pais que associam aprendizagem a cadernos "cheios" de conteúdo - e a expectativa dos estudantes. Entendemos que não é aconselhável apenas atender às expectativas dos estudantes. Porém, já percebemos que não vale a pena impor aquilo que a escola entende como necessário. É preciso conquistar o estudante para a Química.

Conforme descrito anteriormente, Cardoso e Colinvaux (2000) apresentam alguns aspectos motivadores para as aulas de Química e alguns fatores que levam os estudantes a não gostarem dessas aulas. Em nossa análise dos dados, verificamos que alguns fatores são coincidentes aos encontrados por estes autores. Para eles, estudantes são motivados para o estudo da Química por se sentirem atraídos pelos fenômenos da natureza, pelo valor da disciplina para o desenvolvimento dos sujeitos, por aulas práticas e pela utilidade daquele conhecimento para a vida e/ou profissão. Nossos dados mostraram interesses ainda mais amplos. Além de se sentirem motivados por aulas práticas ou experimentos, pelas relações do conteúdo com o contexto e de perceberem a importância da Química, os estudantes claramente anseiam pela diversificação de estratégias, que tornem as aulas mais dinâmicas e, ainda, pela oportunidade de serem mais participativos e assumirem também o protagonismo durante as atividades realizadas.

Em relação à desmotivação, Cardoso e Colinvaux (2000) argumentam que os estudantes não gostam de Química pelo excesso e dificuldade dos conteúdos, pela inutilidade dos conteúdos escolares, pela dificuldade em entender ou assimilar os conteúdos e pela presença de outras áreas como Matemática e Física. Nossos dados mostram resultados semelhantes a esses e acrescentamos, ainda, como aspecto que gera desmotivação, o papel passivo dos estudantes em sala de aula em virtude da metodologia adotada pelos professores.

Concordamos com estes autores quando afirmam que a motivação pelo estudo, principalmente de Química, poderá ser alcançada quando as aulas baseadas na simples memorização de nomes e fórmulas forem abandonadas. Os professores deveriam ampliar o seu papel em sala de aula, fazendo da linguagem uma mediadora entre a cultura do dia-a-dia e a cultura científica. Para isso, a participação dos estudantes é fundamental. A análise dos dados mostrou que seria bom se os professores usassem a energia e a disposição dos estudantes para engajá-los com a Química. Não existe uma 
- Revista de Iniciação à Docência, v. 2, n. 1, 2017 -

Publicação: dezembro, 2017 - ISSN 2525-4332

fórmula que ensine o professor a desenvolver este tipo de trabalho. Como fazer isso é o desafio de cada um de nós!

Nosso interesse inicial era entender o que motiva os estudantes nas aulas de Química, e que elementos contextuais podem engajá-los com essa disciplina escolar. Por meio da análise dos dados percebemos que não há apenas uma resposta para estes questionamentos e nem um conjunto de respostas que possa dar conta da diversidade presente em uma sala de aula. No entanto, encontramos indícios que consideramos importantes.

O primeiro indício se refere à postura passiva que é esperada dos estudantes em muitas aulas. Ao optar por aulas pouco dialogadas, em um processo de transmissão e/ou repasse de informações organizadas, sem atenção para como os estudantes significam essas informações, o professor induz o estudante a usar, como estratégia a memorização dessas informações, e a cópia do que está sendo colocado no quadro de giz para o seu próprio caderno. Isso é descrito pelos estudantes como desestimulante. O fato de vários comentários se referirem às aulas práticas e aulas dialogadas mostra que eles querem participar mais e serem mais ativos em sala de aula. Como a Química é um componente curricular que permite a utilização de atividades interativas e criativas, esta poderia ser amplamente explorada pelos professores.

Reforçando esse fato aparece outro dado interessante: os estudantes relataram considerar os exercícios como momentos de envolvimento com o conteúdo químico estudado. Interpretamos que os exercícios foram destacados não porque os estudantes gostam de aulas de exercícios, mas por se tratar de momentos das aulas nos quais estão envolvidos com as atividades e deixam de exercer o papel de meros expectadores.

Outro indício que encontramos está relacionado à "utilidade" do conhecimento químico. Quando a relação dos conceitos estudados com situações e fatos do cotidiano não é feita pelo professor, provavelmente ele espera que o estudante seja capaz de fazer estas relações. No entanto, o que percebemos dos estudantes é que eles não entendem o motivo pelo qual estudam determinados conceitos químicos. Para os estudantes, tratase de assuntos abstratos e sem "utilidade". Se a Química estuda os materiais nas suas propriedades, constituição e transformações, não seria lógico iniciar este estudo pelos materiais presentes na natureza, explicando-os? Nesse caso, a falada "utilidade" estaria presente e não seria motivo de tanta reclamação dos estudantes. Em nosso entendimento, os professores poderiam explorar mais as relações da Química com o contexto, enfatizando o papel dessa ciência em explicar o mundo material.

Uma evidência da pesquisa que consideramos bastante forte está na diversificação das estratégias e tipos de aula. Sabemos que os jovens adolescentes que frequentam o Ensino Médio são ativos por natureza e gostam de coisas novas. Portanto, qualquer rotina que se repita por muitas vezes se tornará entediante. Mesclar aulas práticas, dialogadas, de exercícios, de leitura de textos, de discussão de vídeos, desde que 
- Revista de Iniciação à Docência, v. 2, n. 1, 2017 -

Publicação: dezembro, 2017 - ISSN 2525-4332

envolvam conteúdo que os permitam evoluir intelectualmente, nos parece bastante indicado.

Ao realizar este trabalho percebemos, por meio do comentário dos estudantes, que a relação estabelecida pelos estudantes com a Química escolar está mais ligada a questões didático-metodológicas do que a conteúdos curriculares propriamente ditos. Apesar dos tantos documentos oficiais tratando do ensinar e aprender na Educação Básica (PCN, Orientações aos PCN etc.), sabemos que não serão eles os responsáveis por transformar o ensino. O professor é o agente de transformação e de mudanças na sala de aula. Temos ciência de que há vários fatores - cursos de formação, salário, administração dos sistemas de ensino etc. - que interferem no trabalho do professor. Porém, o estudante tem desejos em relação às escolas e a aprendizagem é a meta de todo o sistema educacional. Os depoimentos dos estudantes aqui analisados nos mostram a necessidade de encontrar equilíbrio entre esse desejo dos alunos e a forma de desenvolver o conteúdo. Só assim será possível incrementar a aprendizagem.

\section{Referências}

AINLEY, M. Styles of engagement with learning: Multidimensional assessment of their relationship with strategy use and school achievement. Journal of Educational Psychology, v. 85, n. 3, p. 395-405, 1993.

ARROIO, A.; HONÓRIO, K. M.; WEBER, K. C.; HOMEM-DE-MELLO, P.; GAMBARDELLA, M. T. P.; SILVA, A. B. F. O show da Química: motivando o interesse científico. Química Nova, São Paulo, v. 29, n. 1, p. 173-178. 2006.

BARROS, J. A.; REMOLD, J.; SILVA, G. F. S.; TAGLIATI, J. R. Engajamento interativo no curso de Física I da UFJF. Revista Brasileira de Ensino de Física, São Paulo, v. 26, n. 1, p. 63-69. 2004.

BORGES, O.; JULIO, J. M.; COELHO, G. R. Efeitos de um Ambiente de Aprendizagem sobre o Engajamento Comportamental, o Engajamento Cognitivo e sobre a Aprendizagem. In: ENCONTRO DE PESQUISA EM EDUCAÇÃO EM CIÊNCIAS, 5, 2005, Bauru. Atas... Bauru: Associação Brasileira de Pesquisa em Educação em Ciências, 2005. p. 1-12.

BRASIL. Secretaria de Educação Fundamental. Parâmetros Curriculares Nacionais. Brasília: MEC/SEF, 2000.

CARDOSO, S. P.; COLINVAUX, D. Explorando a motivação para estudar Química. Química Nova, São Paulo, v. 23, n. 2, p. 401-404, 2000.

CHASSOT, Á. I. A Educação no Ensino de Química. Ijuí: Editora Unijuí, 1990.

CONNELL, J. P.; SPENCER, M. B.; ABER, J. L. Educational risk and resilience in AfricanAmerican youth: Context, self, action, and outcomes in school. Child Development, v. 65, p. 493-506, abr. 1994.

FARIA, A. F. Engajamento de estudantes em atividade de investigação: estudo em aula de Física do Ensino Médio. 2008. Dissertação (Mestrado em Educação) - Faculdade de Educação da UFMG, Belo Horizonte, 2008. 
- Revista de Iniciação à Docência, v. 2, n. 1, 2017 -

Publicação: dezembro, 2017 - ISSN 2525-4332

FREDRICKS, J. A.; BLUMENFELD, P. C.; PARIS, A. H. School Engagement: potential of the concept, state of the evidence. Review of Educational Research, v. 74, n. 1, p. 59-109, 2004 .

GARNICA, A. V. M. Algumas notas sobre pesquisa qualitativa e Fenomenologia. Interface. Comunicação, Saúde, Educação, v. 1, n. 1, p. 109-122, 1997.

GIORDAN, M. O papel da experimentação no Ensino de Ciências. Química Nova na Escola, São Paulo, n. 10, p. 43-49, nov. 1999.

LEMOS, M. S. A motivação no processo Ensino/Aprendizagem em situação de aula. 1993. Tese (Doutorado em Psicologia e de Ciências da Educação) - Faculdade de Psicologia e de Ciências da Educação da Universidade do Porto, Portugal, 1993.

LIMA, K. E. C.; VASCONCELOS, S. D. Análise da metodologia de ensino de ciências nas escolas da rede municipal de Recife. Ensaio: aval. pol. públ. Educ., Rio de Janeiro, v. 14, n. 52, p. 397-412, jul./set. 2006.

LOPES, A. C. Discursos curriculares na disciplina escolar Química. Ciência \& Educação, Bauru, v. 11, n. 2, p. 263-278. 2005.

MALDANER, O. A. A formação inicial e continuada de professores de Química. ljuí: Editora Inijuí, 2000.

MARKS, H. M. Student engagement in instructional activity: Patterns in elementary, middle and high school years. American Educational Research Journal, v. 37, n. 1, p. 153184, mar. 2000.

MORTIMER, E. F.; SCOTT, P. H. Atividade discursiva nas salas de aula de ciências: uma ferramenta sociocultural para analisar e planejar o ensino. Investigações em Ensino de Ciências, Porto Alegre, v. 7, n. 3, p. 283-306. 2002.

SCHNETZLER, R. P. Concepções e alertas sobre formação continuada de professores de Química. Química Nova, São Paulo, n. 16, p. 15-20, nov. 2002.

SILVA, L. H.; ZANON, L. B. A experimentação no Ensino de Ciências. In: SCHNETZLER, R. P.; ARAGÃO, R. M. R. (Org.) Ensino de Ciências: fundamentos e abordagens. CAPES: UNIMEP, 2000. p. 120-153.

SILVA, R. R.; MACHADO, P. F. L. Experimentação no ensino médio de química: a necessária busca da consciência ético-ambiental no uso e descarte de produtos químicos - um estudo de caso. Ciência \& Educação, Bauru, v. 14, n. 2, p. 233-249. 2008.

SINGH, K.; GRANVILLE, M.; DIKA, S. Mathematics and Science achievement: Effects of motivation, interest, and academic engagement. The Journal of Educational Research, $v$. 95, n. 6, p. 323-332, jul./ago. 2002.

STRACK, R.; MARQUES, M.; DEL PINO, J. C. Por um outro percurso da construção do saber em educação química. Química Nova na Escola, São Paulo, v. 31, n. 1, p. 18-22, fev. 2009 . 